\title{
The establishment of Scotland's rarest freshwater fish, the vendace (Coregonus albula), in conservation refuge sites
}

\author{
A.A. Lyle ${ }^{1}$, C.W. Bean ${ }^{2}$, H.M. Honkanen ${ }^{3}$, J.P. Koene ${ }^{3}$ \& C.E. Adams ${ }^{3}$ \\ ${ }^{1}$ ALP, 18 John Knox Road, Longniddry, East Lothian EH32 0LP \\ ${ }^{2}$ Scottish Natural Heritage, Mariner Court, 8 South Avenue, Clydebank G81 2NR \\ ${ }^{3}$ Scottish Centre for Ecology \& the Natural Environment, University of Glasgow, Rowardennan, Glasgow G63 0AW \\ E-mail: colin.adams@glasgow.ac.uk
}

\begin{abstract}
In recent decades conservation measures for the rarest freshwater fish in the U.K., the vendace (Coregonus albula), have included attempts to form conservation refuge populations in Scotland. Here we report that at two of these refuge sites where the status of the introduced vendace was previously unknown (Loch Earn and Daer Reservoir) surveys have established that vendace are reproducing successfully in situ, albeit that these populations appear to be relatively numerically small. At a third site, Loch Valley, there was no evidence of vendace in the survey, but it is possible that a small, but as yet undetectable population is in the process of establishing.
\end{abstract}

\section{INTRODUCTION}

The vendace is the rarest freshwater fish in the U.K., having only ever been recorded in historical times from four locations. Two of these are in the English Lake District: Bassenthwaite Lake and Derwent Water; and two in southern Scotland: Castle Loch and Mill Loch, adjacent to the town of Lochmaben in Dumfriesshire (Maitland, 2007) (Fig. 1). Of these, the Bassenthwaite Lake population was thought to have been lost in 2008 (Winfield et al., 2012), as a result of eutrophication of the lake, sedimentation of the vendace spawning grounds and the introduction of non-native fish species, although there is now evidence of their re-establishment there, most likely by re-colonisation by vendace from Derwent Water which has a direct river connection into Bassenthwaite Lake (Winfield \& Gowans, 2014; Winfield et al., 2017). In Scotland, both native vendace populations have been lost. The Castle Loch population in the early 20th century, mostly likely as the result of eutrophication from a new sewage works; the Mill Loch population sometime between 1966 and around 1975, also mostly likely as the result of eutrophication but in this case from diffuse pollution (Maitland \& Lyle, 2013). The rarity of vendace in the U.K. and the loss of three of the four known historical populations, including both Scottish populations, prompted the then Nature Conservancy Council in 1986 to initiate conservation management actions which included efforts to establish new vendace populations in selected sites, to which they were not native, to act as conservation refuge or "Ark" sites. Since 1996, Scottish Natural Heritage and the Environment Agency (England) have promoted, through the U.K. Biodiversity Action Plan Steering Group (Vendace), a continuation of the vendace conservation programme and there are now five water bodies where attempts to create refuge populations have been made: Loch Earn, Daer Reservoir, Loch Valley and Loch Skeen in Scotland, plus Sprinkling Tarn in Cumbria (Fig. 1).

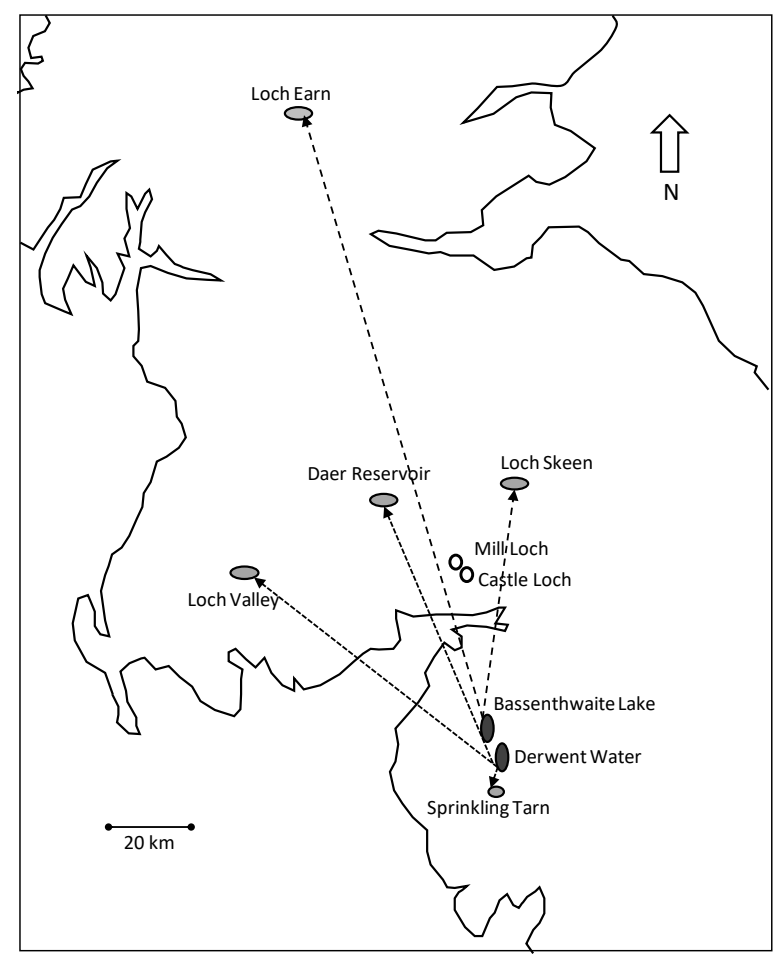

Fig. 1. A map showing the locations of the vendace (Coregonus albula) source population sites: Bassenthwaite Lake and Derwent Water in the English Lake District, Cumbria; and the conservation refuge sites: Loch Earn, Daer Reservoir, Loch Valley and Loch Skeen in Scotland, plus Sprinkling Tarn in Cumbria. The locations of the now extinct Castle Loch and Mill Loch vendace populations in Scotland are also shown.

The translocation of 17,550 fry and 47,500 eyed eggs to Loch Skeen between 1997 and 1999 has resulted in an established, self-sustaining population of vendace there and is fully reported elsewhere (Maitland \& Lyle, 2013; 
Adams et al., 2014). The success of the vendace introduction to Sprinkling Tarn remains unknown.

Here we report on recent surveys at the other three conservation refuge sites to investigate the status of vendace there.

\section{METHODS}

Previous attempts to assess whether fish translocations have been successful in Scotland have relied on the use of gillnetting and hydroacoustic approaches (Maitland $e t$ al., 2003, 2007). This was based on the understanding that fish are more active and susceptible to capture in gill nets during summer periods, and that vendace occupy the pelagic zone of standing waters at night and are easy to detect and count using hydroacoustic techniques.

The approach taken for Loch Earn and Daer Reservoir differed from this in that surveys were undertaken during the known spawning periods for vendace in the U.K., and sampling effort was targeted towards habitats that matched the spawning substrates considered to be similar to those used elsewhere (Coyle \& Adams, 2011). The survey at Loch Valley, however, was conducted in summer since winter access to this more remote upland loch could be uncertain.

\section{Loch Earn (NN644237)}

Loch Earn, in Perthshire, is one of the larger Scottish lochs. It has a surface area of 1,013 ha, a maximum depth of $87.5 \mathrm{~m}$ and a mean depth of $42.0 \mathrm{~m}$ (Murray \& Pullar, 1910). It has a length of $10.4 \mathrm{~km}$ and an average width of about $1 \mathrm{~km}$ and lies at an altitude of $97 \mathrm{~m}$ aod (Fig. 2).

Loch Earn was surveyed between 27th and 29th November 2016 during the vendace spawning period. Single mesh monofilament benthic gill nets $(30 \mathrm{~m} \mathrm{x}$ $1.5 \mathrm{~m}$ and $30 \mathrm{~m} \times 3.0 \mathrm{~m}$ ) of mesh sizes likely to capture adult vendace (i.e. 18.5, 22 and $25 \mathrm{~mm}$ mesh, knot-toknot) were used and set overnight - six nets on 27 th/28th and four nets on 28th/29th. These nets were set onto the loch bed in littoral and sub-littoral zones of the loch (2-12 m depth) in areas which appeared to be suitable vendace spawning sites (comprising well washed gravel to cobble sized substrate) (Fig. 2).

\section{Daer Reservoir (NS980086)}

Daer Reservoir lies in the Lowther Hills in Lanarkshire within the River Clyde catchment. It is a public water supply controlled by Scottish Water. The reservoir measures 202 ha in surface area, with a maximum depth of $37.1 \mathrm{~m}$ and lies at an altitude of $342 \mathrm{~m}$ aod (Fig. 3). Daer Reservoir was surveyed on 5th/6th December 2017 during the spawning period for vendace. A combination of benthic Norden survey gill nets (Appelberg et al., 1995) (see below) and single mesh size nets (30 m x $1.5 \mathrm{~m}$ and 18.5, 22 and $25 \mathrm{~mm}$ mesh sizes) were used. Five nets (two Norden nets and one each of the three single mesh size nets) were deployed at sites that appeared suitable for vendace spawning (well washed gravel to cobble sized substrate) in water depths of 4-19 $\mathrm{m}$ on the 5th December, left overnight and retrieved the following morning (Fig. 3).

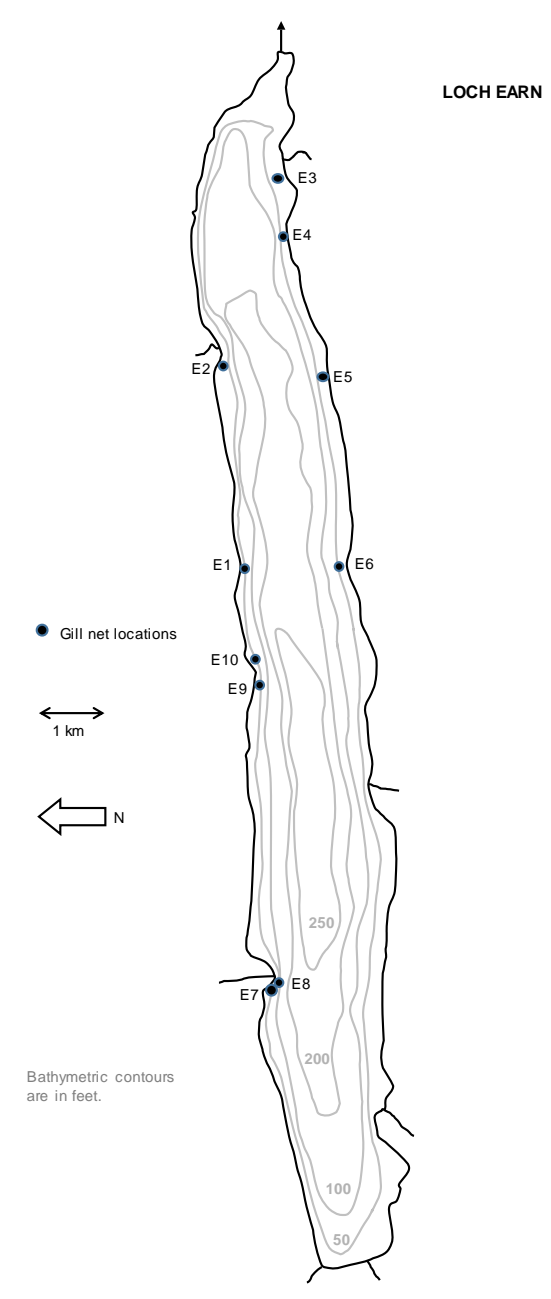

Fig. 2. Loch Earn, Scotland showing the 10 benthic gill net locations (E1-E10) used in the survey. Depth contours are in feet (derived from Murray \& Pullar, 1910).

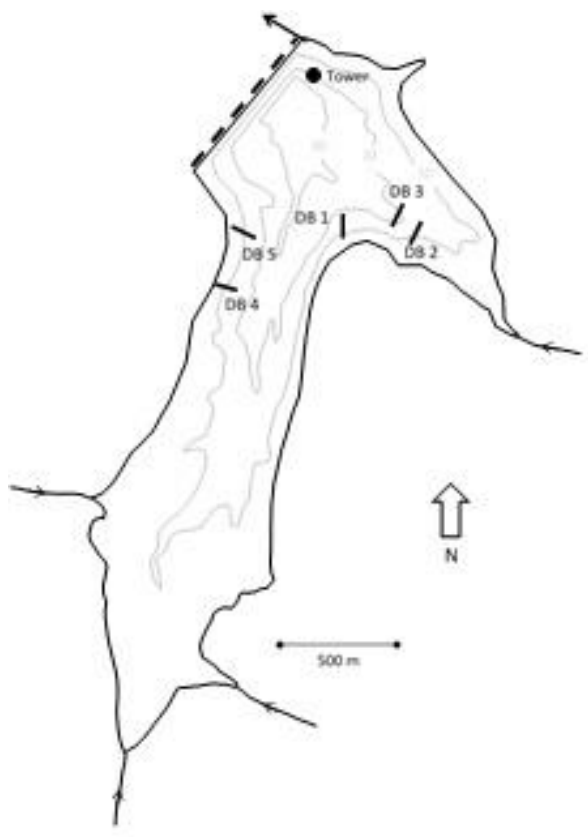

Fig. 3. Daer Reservoir, Scotland showing the locations of the five benthic survey nets. Bathymetric contours are in metres. 


\section{Loch Valley (NX444817)}

Loch Valley is located in the Galloway Forest Park in southwest Scotland. The loch is 35.8 ha in area with a maximum depth of $17.2 \mathrm{~m}$ and lies at an altitude of $322 \mathrm{~m}$ aod (Fig. 4).

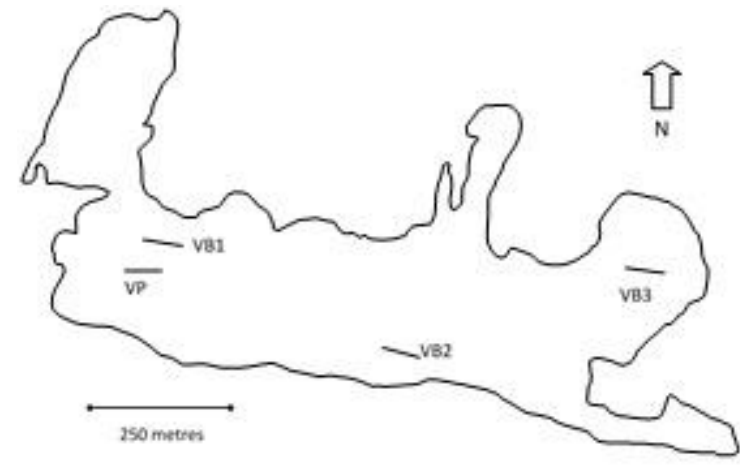

Fig. 4. Loch Valley, Scotland showing the locations of the four survey net sites $(\mathrm{VP}=$ pelagic, $\mathrm{VB}=$ benthic $)$.

Loch Valley was surveyed during the summer feeding period for vendace. The survey was conducted overnight on 3rd/4th July 2017 using three Norden benthic survey gill nets $(30 \mathrm{~m} \times 1.5 \mathrm{~m})$ set onto the loch bed, and one Norden pelagic net $(27.5 \mathrm{~m} \mathrm{x} 6 \mathrm{~m})$ set at the water surface. Norden net types comprise 12 (benthic) and 11 (pelagic) panels with mesh sizes 8-55 mm knot-to-knot
(Appelberg et al., 1995). The survey here was deliberately of low intensity to avoid any undue impact on a potentially newly establishing fish population (Fig. 4).

Full details of these surveys are given in the official reports to Scottish Natural Heritage: Adams \& Lyle (2017) for Daer Reservoir and Loch Valley, and Lyle \& Adams (2016) for Loch Earn.

\section{RESULTS}

\section{Loch Earn}

Gill netting surveys at Loch Earn captured brown trout (Salmo trutta) $(\mathrm{N}=186)$, Arctic charr (Salvelinus alpinus) $(\mathrm{N}=21)$, and a single vendace. The vendace was $209 \mathrm{~mm}$ fork length and a 5+ years old male which was exuding sperm indicating that it was in spawning condition at that time.

\section{Daer Reservoir}

Gill netting surveys at Daer Reservoir recorded brown trout $(\mathrm{N}=37)$ and a single vendace (Fig. 5) which was collected in the $25 \mathrm{~mm}$ single mesh size net. The vendace was $211 \mathrm{~mm}$ in length and weighed $105 \mathrm{~g}$ and was a female that had recently spawned.

\section{Loch Valley}

Surveying at Loch Valley recorded brown trout $(\mathrm{N}=25)$ but no vendace were found.

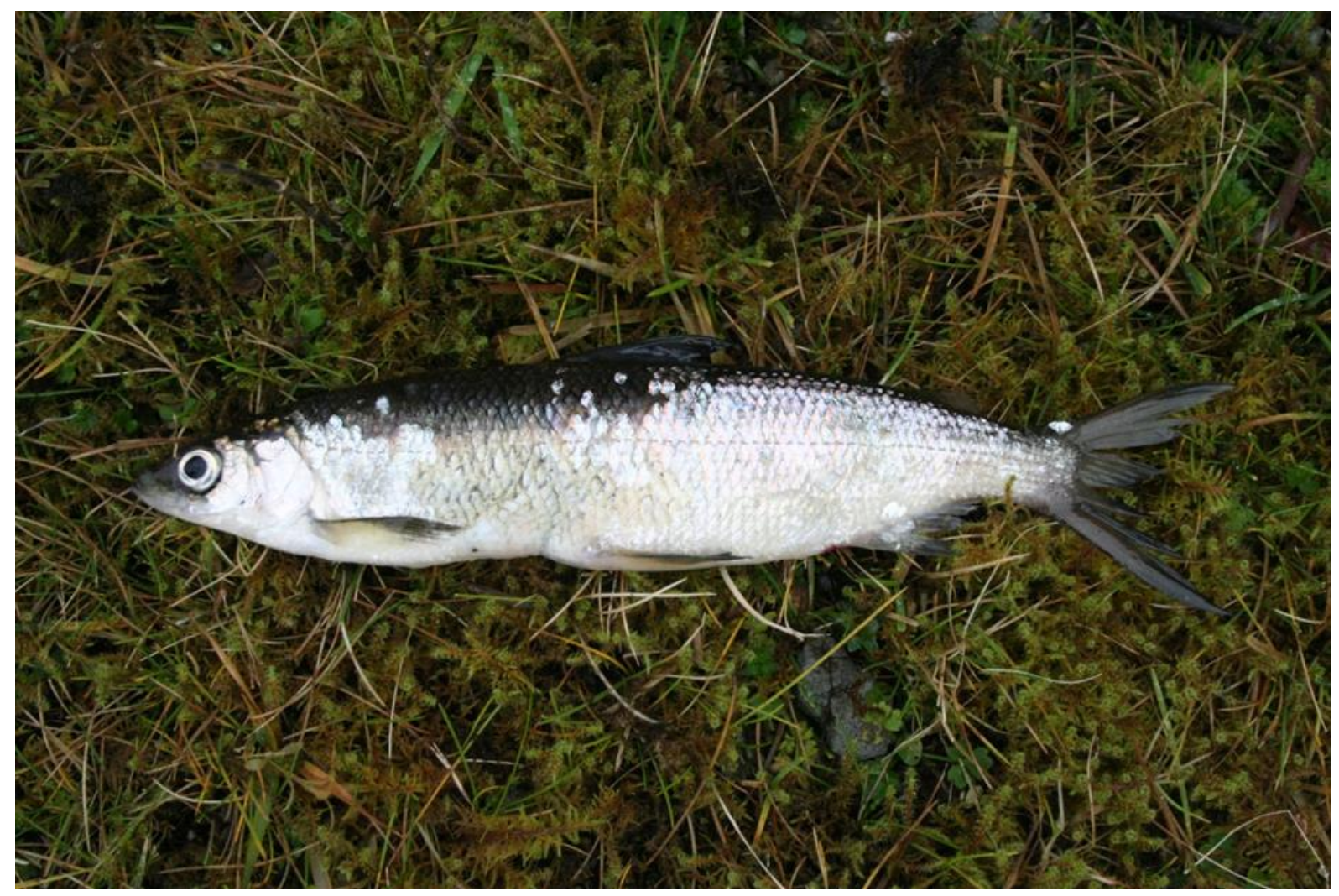

Fig. 5. The first vendace (Coreginus albula) recorded at the Daer Reservoir, Scotland conservation refuge site in 2017. 


\section{DISCUSSION}

Background - conservation translocations at the refuge sites

The methodology of refuge site selection and practical translocations of vendace for conservation management in Scotland have been reported more fully elsewhere (Maitland \& Lyle, 1990, 2013; Adams et al., 2014), but a brief summary of relevant elements for the three sites examined in this study is given here.

Loch Earn In 1989, 8,400 vendace fry from the Bassenthwaite Lake population were introduced into Loch Earn (Maitland \& Lyle, 1990). There were no subsequent reports of vendace having established there from (unconnected) netting surveys by others, or by anglers, until a single specimen was caught by an angler in 2005. Consequently, a dedicated gill netting and hydroacoustic survey was carried out in 2007 (Maitland et al., 2007) but vendace were not detected. A second vendace was reported caught by an angler in 2012 and in 2016 the survey for vendace reported here was commissioned by Scottish Natural Heritage.

Daer Reservoir Translocations of vendace from the Derwent Water population were made to Daer Reservoir in 1998, 2005 and 2008. In total 25 adults, 12,800 unfed fry and 32,300 eggs were transferred. Extensive gill netting surveys in 2003 (Maitland et al., 2003) and again in 2009 (Lyle et al., 2009) both failed to detect any vendace and the status of the conservation translocation population remained uncertain. In 2017 Scottish Natural Heritage commissioned a further survey, the results of which are given above.

Loch Valley An introduction of vendace to this site was carried out in 1968 but it failed to establish probably due to acidification (Maitland et al., 2013). Water quality monitoring by Marine Scotland Science has shown that water quality $(\mathrm{pH})$ has shown a consistent recovery from acidification and is now able to support salmonid fish (Harriman et al., 2003).

In 2011, 70,000 eyed eggs collected from spawning vendace from Derwent Water were translocated to Loch Valley (Lyle \& Dodd, 2011). Prior to the survey reported above, there had been no attempt to assess the status of this translocation.

\section{Conclusions from this survey}

Loch Earn

Although only a single vendace was collected from Loch Earn, this result shows that a population of vendace has established and that it has survived for over 27 years, equivalent to at least nine generations since translocation to this location in 1989. Although this survey does not provide for a robust analysis of vendace population size, the very low catch rate compared with that of brown trout and Arctic charr and the absence of any vendace in the 2007 survey (Maitland et al., 2007) suggest that only a very small population of vendace has established in Loch Earn.

\section{Daer Reservoir}

Although three separate introductions of vendace were made to Daer Reservoir over a ten-year period (1998-2008) and by different means of material transfer (adults, fry and eggs) it cannot be concluded which of those transfers or methods was successful. However, since vendace live for five to six years (Maitland \& Campbell, 1992), the capture of even a single specimen indicates that there has been successful reproduction for at least three generations of vendace in Daer Reservoir since the last translocation in 2008. The indications from this survey are that the population is currently relatively small and if it was one of the later translocations that was first successful it is possible that the population is only now in the process of fully establishing itself.

\section{Loch Valley}

The lack of a record of vendace at Loch Valley does not necessarily lead to the conclusion that vendace have not established there. It is exceedingly difficult to establish presence or absence of any animal that is possibly at low abundance with any low intensity survey technique. The earlier, very extensive and intensive surveying of Loch Earn indicates how easy it is to miss detection of a numerically small fish population. It remains possible that the vendace introduction to Loch Valley, which was made only six years ( $c a$. two generations) before the survey reported here, has established a small but as yet undetected population.

\section{REFERENCES}

Adams, C.E. \& Lyle, A.A. 2017. Assessing the Status of Vendace in Loch Valley and Daer Reservoir, 2017. Scottish Natural Heritage Commissioned Report.

Adams, C.E., Lyle, A.A., Dodd, J.A., Bean, C.W., Winfield, I.J., Gowans, A.R.D., Stephen, A. \& Maitland, P.S. (2014). Translocation as a conservation tool: case studies from rare freshwater fishes in Scotland. The Glasgow Naturalist 26(1), 17-24.

Appelberg, M., Berger, H.M., Hesthagen, T., Kleiven, E., Kurkilahti, M., Raitaniemi, J. \& Rask, M. (1995). Development and intercalibration of methods in nordic freshwater fish monitoring. Water, Air, and Soil Pollution 85, 401-406. https://doi.org/10.1007/BF00476862

Coyle, S. \& Adams, C.E. (2011). Development of a Methodology for the Assessment of the Quality of Vendace Spawning Substrate and its Application to Sites in Scotland and Northern England. Scottish Natural Heritage Commissioned Report No. 308.

Harriman, R., Watt, A., Christie, A., Moore, D., McCartney, A. \& Taylor, E. (2003). Quantifying the effects of forestry practices on the recovery of upland streams and lochs from acidification. The Science of the Total Environment 310, 101-111. https://doi.org/10.1016/S0048-9697(02)00626-5

Lyle, A.A \& Adams, C.E. (2016). Assessing the Presence of Vendace in Loch Earn, 2016. Scottish Natural Heritage Commissioned Report No. 976.

Lyle, A.A. \& Dodd, J.A. (2011). Translocation of Vendace from Derwent Water to Safe Refuge Locations (2010/11). Report to the Environment 
Agency.

Lyle, A.A., Maitland, P.S., Winfield, I.J. \& Fletcher, J.M. (2009). Assessment of the Status of Vendace in Daer Reservoir. Scottish Natural Heritage Commissioned Report.

Maitland, P.S., \& Campbell, R. (1992). Freshwater Fishes of the British Isles. Harper Collins, London.

Maitland, P.S. \& Lyle, A.A. (2013). Ex situ and in situ approaches, including assisted reproduction, for the conservation of native species of charr (Salmonidae) and whitefish (Coregonidae) in Scotland. International Zoo Yearbook 47, 129-139. https://doi.org/10.1111/j.1748-1090.2012.00192.x

Maitland, P.S., Lyle, A. \& Winfield, I. (2003). Survey of Vendace in Daer Reservoir and Loch Skene. English Nature Contract No EIT 34-01-006. Shefffield.

Maitland, P.S., Lyle, A., Winfield, I. \& Fletcher, J. (2007). Vendace in Loch Earn. Scottish Natural Heritage Commissioned Report No. 284.

Maitland, P.S. (2007). Scotland's Freshwater Fish: Ecology Conservation and Folklore. Trafford Publishing, Bloomington, U.S.A.

Maitland, P.S. \& Lyle, A.A. (1990). Practical conservation of British fishes: current action on six declining species. Journal of Fish Biology 37, 255256.

https://doi.org/10.1111/j.1095-8649.1990.tb05057.x

Murray, J. \& Pullar, L. (1910). Bathymetrical Survey of the Scottish Fresh-water Lochs. Challenger Office, Edinburgh.

Winfield, I.J. \& Gowans, A.R.D. (2014). U.K.'s rarest freshwater fish 'reappears'. Saving Freshwater Fishes and Habitats: Newsletter of the IUCN SSC/WI Freshwater Fish Specialist Group 4: 16.

Winfield, I.J., Adams, C.E., Bean, C.W., Durie, N.C., Fletcher, J.M., Gowans, A.R.D. et al. (2012). Conservation of the vendace (Coregonus albula), the U.K.' $\mathrm{s}$ rarest freshwater fish. Advances in Limnology 63, 547-559.

Winfield, I.J., Fletcher, J.M. \& James, J.B. (2017). The 'reappearance' of vendace (Coregonus albula) In the face of multiple stressors in Bassenthwaite Lake, U.K. Fundamental and Applied Limnology 189, 227-233.

https://doi.org/10.1127/fal/2016/0799 